\title{
EFFECT OF HEAT TREATMENT ON MICROSTRUCTURE AND IMPACT TOUGHNESS OF Ti-6AI-4V MANUFACTURED BY SELECTIVE LASER MELTING PROCESS
}

\begin{abstract}
This study manufactured Ti-6Al-4V alloy using one of the powder bed fusion 3D-printing processes, selective laser melting, and investigated the effect of heat treatment $\left(650^{\circ} \mathrm{C} / 3 \mathrm{hrs}\right)$ on microstructure and impact toughness of the material. Initial microstructural observation identified prior- $\beta$ grain along the building direction before and after heat treatment. In addition, the material formed a fully martensite structure before heat treatment, and after heat treatment, $\alpha$ and $\beta$ phase were formed simultaneously. Charpy impact tests were conducted. The average impact energy measured as $6.0 \mathrm{~J}$ before heat treatment, and after heat treatment, the average impact energy increased by approximately $20 \%$ to $7.3 \mathrm{~J}$. Fracture surface observation after the impact test showed that both alloys had brittle characteristics on macro levels, but showed ductile fracture characteristics and dimples at micro levels.

Keywords: Selective Laser Melting, Ti-6Al-4V, Microstructure, Impact Toughness, Heat Treatment
\end{abstract}

\section{Introduction}

Selective laser melting (SLM) is a 3D metal printing process that builds three-dimensional parts by layering powder based on a computer aided design (CAD) model. This process uses a high-energy laser source to selectively melt the layered powder, and it is a powder bed fusion (PBF) method that builds complex, elaborate free-form parts by repeating the process [1]. Compared to conventional production techniques (casting, cold working, machining, etc.), 3D printing technology such as SLM has nearly no waste materials, has fewer production stages and can easily apply design changes, which makes it one of the most highly regarded technologies in various fields [2]. SLM has the advantage of excellent dimension accuracy and a fast cooling rate $\left(10^{5} \sim 10^{8} \mathrm{~K} / \mathrm{s}\right)$ compared to other E-beam melting (EBM) and direct energy deposition (DED) 3D printing processes [3].

Ti-6Al-4V (hereinafter referred to as "Ti64") alloy is a widely used material and the most critical material in the Ti market due to its outstanding corrosion resistance, bio-affinity and specific strength. It is applied in the aerospace, medical, military and automotive fields due to its capability of controlling its microstructure through heat treatment as an $\alpha+\beta$ alloy [4]. However, Ti64 alloy has high oxygen affinity in a molten state, which causes various problems during parts production, and this leads to an increase in process cost. Furthermore, it requires postprocessing for parts production, which leads to further process cost increases during complex, elaborate parts production.
Some studies are attempting to apply SLM as a suitable method for producing complex, elaborate parts with Ti64 alloy. In particular, studies focusing on a wide range of properties such as microstructural observations according to heat treatment, layering direction, process type and process variable control [5], and mechanical property evaluations including directional tension, fracture toughness and high-cycle fatigue [6] are being conducted.

To use SLMed Ti64 alloy as a structural material, it is important to achieve toughness and ductility. Thus, there is a need for studies that identify methods of increasing toughness through heat treatment. However, the number of studies attempting to achieve toughness in SLMed Ti64 alloy through heat treatment is very low. Moreover, there is no study on impact behavior identified using the linked interpretation of impact energy, microstructure and fracture surface.

The present study investigated the effects of heat treatment on the microstructure and impact toughness properties of SLMed Ti64 alloy. In addition, the fracture surface of the alloy after impact test was analyzed to identify the effect of heat treatment on impact fracture behavior of SLMed Ti64 alloy.

\section{Experimental method}

This study used Ti-6Al-4V alloy with $74.5 \mathrm{~mm}$ building direction (BD), $12 \mathrm{~mm}$ transverse direction (TD) and $7 \mathrm{~mm}$ printing direction (PD) manufactured by EOS of Germany. The

\footnotetext{
* INHA UNIVERSITY, 100 INHA-RO, INCHEON, 22212, KOREA

** KOREA INSTITUTE OF MATERIALS SCIENCE, CHANGWON-SI, REPUBLIC OF KOREA

*** RESEARCH INSTITUTE OF INDUSTRIAL SCIENCE \& TECHNOLOGY, POHANG-SI, REPUBLIC OF KOREA

**** KOREA ATOMIC ENERGY RESEARCH INSTITUTE, DAEJEON-SI, REPUBLIC OF KOREA

\# Corresponding author: keeahn@inha.ac.kr
} 
chemical composition analysis of Ti64 alloy using an X-ray fluorescence spectrometer (XRF) identified Ti as well as 5.5 Al, $3.87 \mathrm{~V}$ and $0.22 \mathrm{Fe}$ (wt.\%). The alloy was heat treated (stress relieving) in an argon atmosphere of $650^{\circ} \mathrm{C}$ for 3 hours, and then furnace cooled.

A Charpy impact test was performed to measure toughness, and the size of Charpy impact specimen was $5 \times 5 \times 27.5 \mathrm{~mm}^{3}$. The impact test equipment used was the SI-1B from SATEC. Hardness was measured using the Vickers hardness equipment, and the hardness was calculated by taking the average of 12 trials with a constant load of $2 \mathrm{Kgf}$ and holding time of 10 seconds.

To observe the phase change of SLMed Ti64 alloy according to heat treatment, an X-ray diffractometer (XRD Ultima IV) was used for analysis. Also, to observe the microstructure before and after heat treatment, the alloy was cut at a vertical angle in the transverse direction (TD) and mechanically polish using $\mathrm{SiC}$ paper (\#100 \#2000) and $1 \mu \mathrm{m}_{2} \mathrm{O}_{3}$ slurry. The cut alloy was then etched with $50 \mathrm{ml} \mathrm{H} \mathrm{H}_{2} \mathrm{O}+25 \mathrm{ml} \mathrm{HNO}_{3}+5 \mathrm{ml} \mathrm{HF}$ solution before optical microscope $(\mathrm{OM})$ and scanning electron microscopy (SEM) observations were made. To perform EBSD analysis, the cut alloy after the above grinding condition was then finely ground with colloidal silica and step sized to 0.9 $\mu \mathrm{m}$, and data analysis was performed using the AZTecHKL program. To identify impact behavior after impact test, SEM (Tescan VEGA II LMU) and field emission SEM (FE-SEM) (Tescan LYRA 3 XMH) were employed to observe the fracture surface of the specimen.

\section{Results and discussion}

Fig. 1 is the observation results of the initial microstructures of SLMed Ti64 alloys before and after heat treatment. Both specimens featured coarse columnar grains with $100 \mu \mathrm{m}$ width along the building direction. This is a phenomenon unique to $3 \mathrm{D}$ printed materials, and it is known to be caused by heat release in a single direction [7]. Macroscopic differences of the microstructures are that there were significantly less disk-type defects in the heat-treated specimen than in the as-fabricated specimen, and dark bands, which are expected to be laser track lines, also disappeared in the heat-treated specimen. The relative density was measured using Archimedes method, and the density slightly increased from $4.372 \mathrm{~g} / \mathrm{cm}^{3}$ to $4.411 \mathrm{~g} / \mathrm{cm}^{3}$ after heat treatment. This is interpreted as densification occurring even in stress relief heat treatment condition.

Meanwhile, focused on the internal columnar grains, there are fine acicular-type structure were seen that are considered to be $\alpha^{\prime}$-martensite. In general, the rapid cooling of $\alpha+\beta$ Ti64 alloy is known to form $\alpha^{\prime}$-martensite phase, and in the case of SLM, there were cases where fully martensite structures were formed according to the rapid cooling rate [3].

Fig. 2 is the X-ray diffraction analysis result performed to identify phases. First, a brief observation of the two specimens at $20 \sim 100^{\circ} 2$-Theta(a) revealed single phases mainly composed of $\alpha^{\prime}$ phase. However, in the slow scanning results of the two at 34 44 2 -Theta (b), the peak shift of $\alpha^{\prime}$ phase was found and some $\beta$-peak was observed. This phenomenon is known to occur during the decomposition of the $\alpha^{\prime}$ phase, and due to such, the as-fabricated specimen featured a single phase of $\alpha^{\prime}$ and the heat-treated specimen featured $\alpha^{\prime}$ phase as well as $\alpha$ and $\beta$ phases. To understand the microstructural difference, high magnification observation using SEM was conducted on the initial microstructure, and the results are as shown in Fig. 3. The as-fabricated specimen(a) showed a dominant dispersion of $\alpha^{\prime}$ phase, and the heat-treated specimen(b) featured $\alpha^{\prime}$ phase as well as $\alpha$ and $\beta$ phases. The thickness of $\alpha^{\prime}$ in the as-fabricated specimen was approximately $0.1 \sim 1 \mu \mathrm{m}$, and the thickness was confirmed to increase according to heat treatment.

EBSD analysis results of the SLMed Ti64 alloys are shown in Fig. 4. Image quality (IQ) map observation found prior- $\beta$ grain elongated along the building direction in both the as-fabricated (a) and heat-treated (b) specimens. The misorientation angle distribution analysis result $(\mathrm{c}, \mathrm{d})$ confirmed that both alloys had a dominant fraction of low angle boundary (LABs) at an angle less than $5^{\circ}$ and high angle boundary (H ABs) at an angle around $60^{\circ}$. This unique characteristic of HABs at around $60^{\circ}$ is considered to be caused by the sudden dislocation density increase of $\mathrm{Ti}$ and $\mathrm{Ti}$ alloy martensite structure during the twinning of
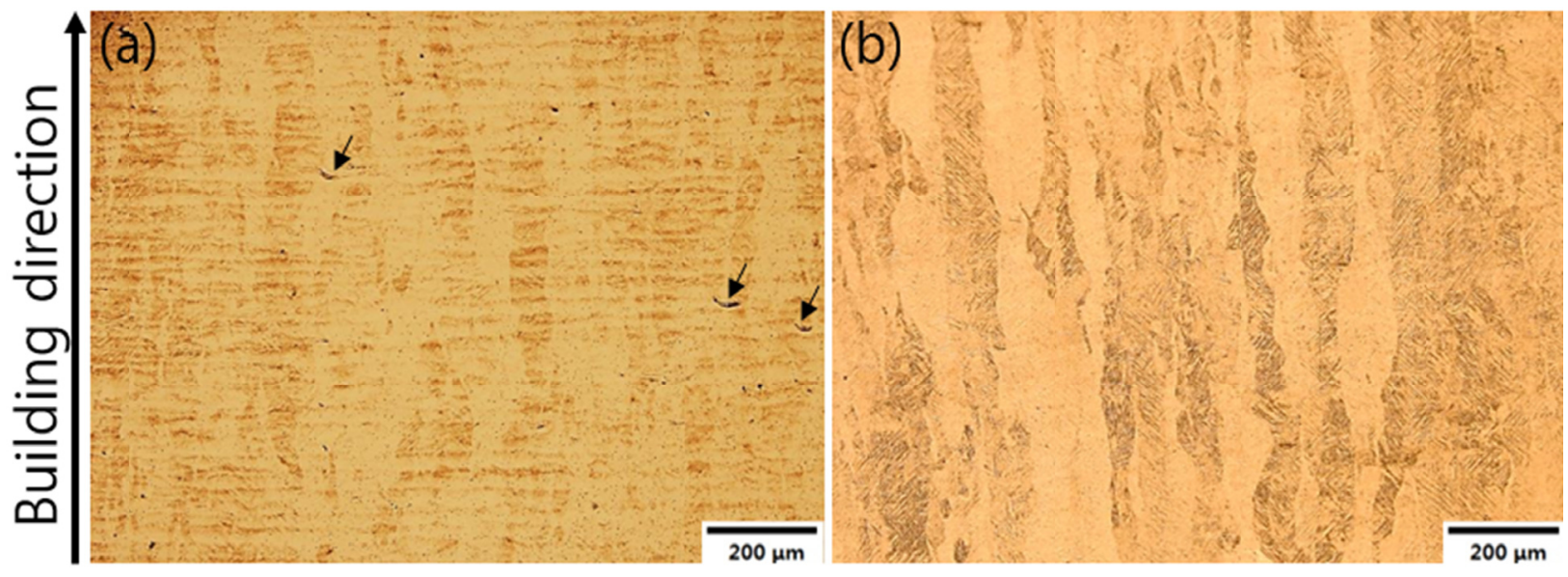

Fig. 1. Optical micrographs illustrating the wide columnar grains of the (a) as-fabricated specimen and (b) heat-treated specimen 

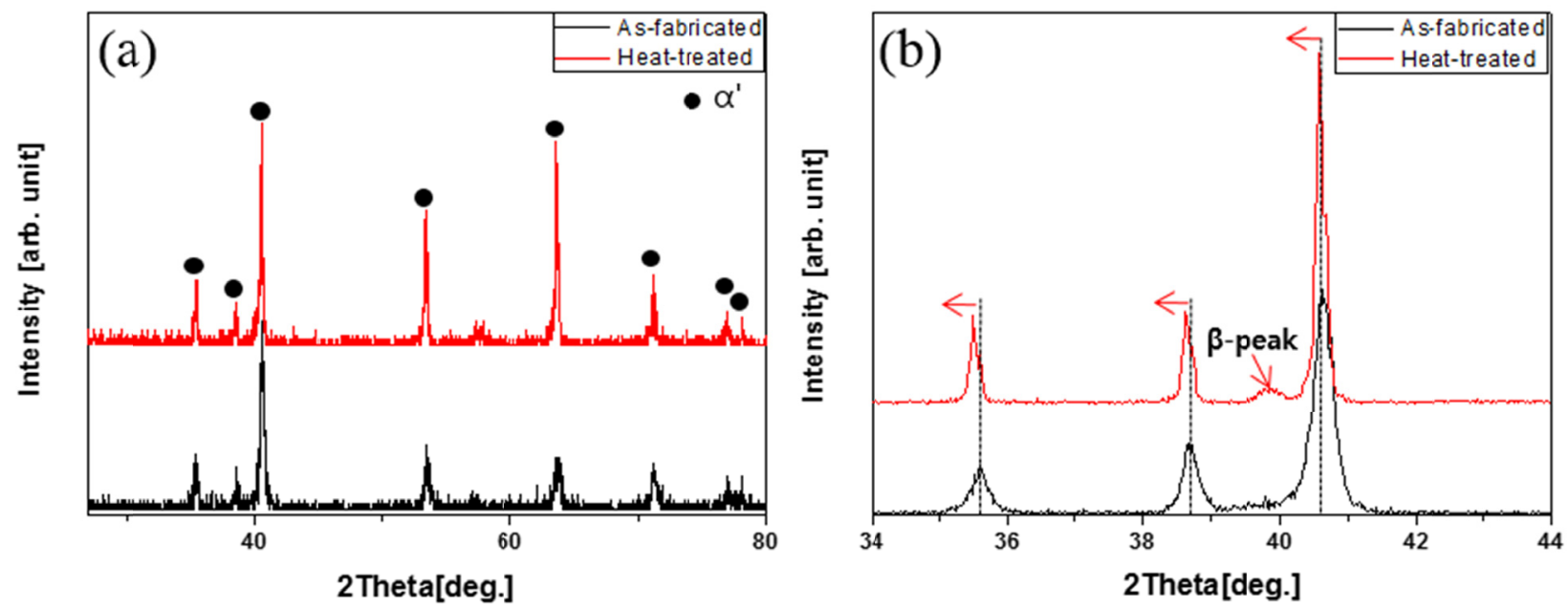

Fig. 2. X-ray diffraction analysis results of the as-fabricated specimen and heat-treated specimen; (a) 20 100 2theta, (b) 34 44 2theta
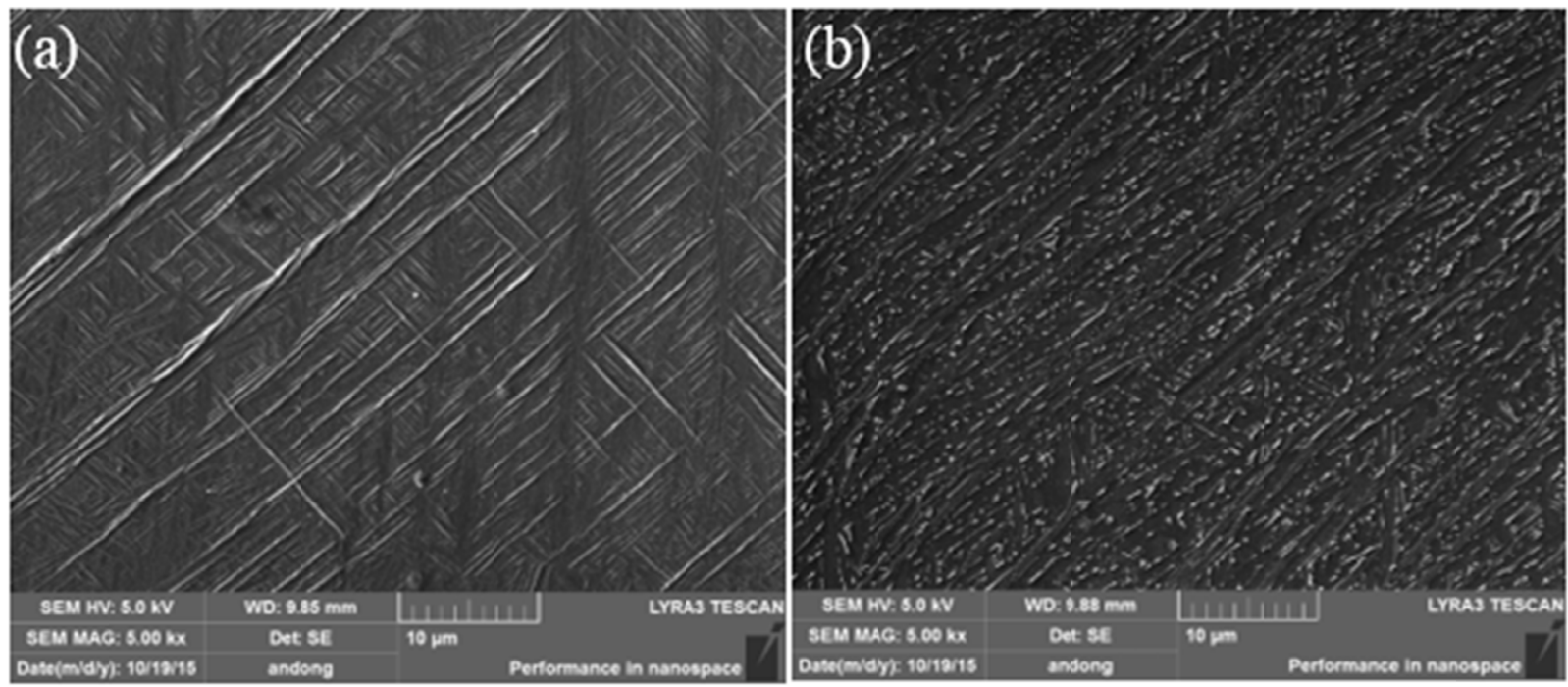

Fig. 3. SEM micrographs of SLMed Ti-6Al-4V alloy; (a) as-fabricated specimen and (b) heat-treated specimen

individual plates. According to Simonelli et al. [8], SLMed Ti64 alloy has approximately five or six types of $\alpha^{\prime}$ phases, and most of them have a $60^{\circ}$ misorientation. A LABs dispersion ratio of heat-treated specimen (d) is lower than that of as-fabricated specimen (c). It is considered to be caused by the dislocation density decreasing according to microstructural changes such as phase decomposition during heat treatment.

The hardness of the two specimens measured BD $448 \mathrm{Hv}$, TD $413 \mathrm{Hv}$ and PD 401.9 Hv for the as-fabricated specimen, and BD $367.8 \mathrm{Hv}$, TD $369 \mathrm{Hv}$ and PD $368 \mathrm{Hv}$ for the heat-treated specimen. One thing to note is that the hardness of BD before heat treatment had high anisotropy, but such anisotropy disappeared after heat treatment.

The impact test results of SLMed Ti64 alloy were obtained. After repeated tests, the average impact energies were $6.0 \mathrm{~J}$ for the as-fabricated and $7.3 \mathrm{~J}$ for the heat-treated specimens. It was confirmed that impact energy increased by approximately $20 \%$ after heat treatment. Ti64 alloy is generally known to have wide variation of impact energy along the fraction of the hexagonal closed packed $\alpha^{\prime}$ phase and body centered cubic $\beta$ phase. There were also significantly different impact energies on the lamellar microstructure with $34 \mathrm{~J} \sim 49 \mathrm{~J}$, bimodal microstructure with $27 \mathrm{~J} \sim 36 \mathrm{~J}$, and equiaxed microstructure with $8 \mathrm{~J} \sim 41 \mathrm{~J}[9]$. Furthermore, there were some differences according to direction, but in the case of SLMed Ti64 alloy, which has a high martensite phase fraction, it had impact energy of approximately $4 \mathrm{~J} \sim 10 \mathrm{~J}[10]$.

In order to identify the impact behavior above, macroscopic fracture surface observation of both the as-fabricated and heat-treated specimen was conducted, and the results are shown in Fig. 5. The fracture surfaces of the as-fabricated (a) and heat-treated (b) specimens were similar to the impact fracture surfaces of brittle materials. It is generally known that in the case of ductile materials, a dull appearance with severe surface roughness is observed and in the case of brittle materials, a bright appearance is observed after an impact test. Accordingly, it is considered that both specimens have martensite with high brittleness, a smooth fracture surface, and represent low impact 

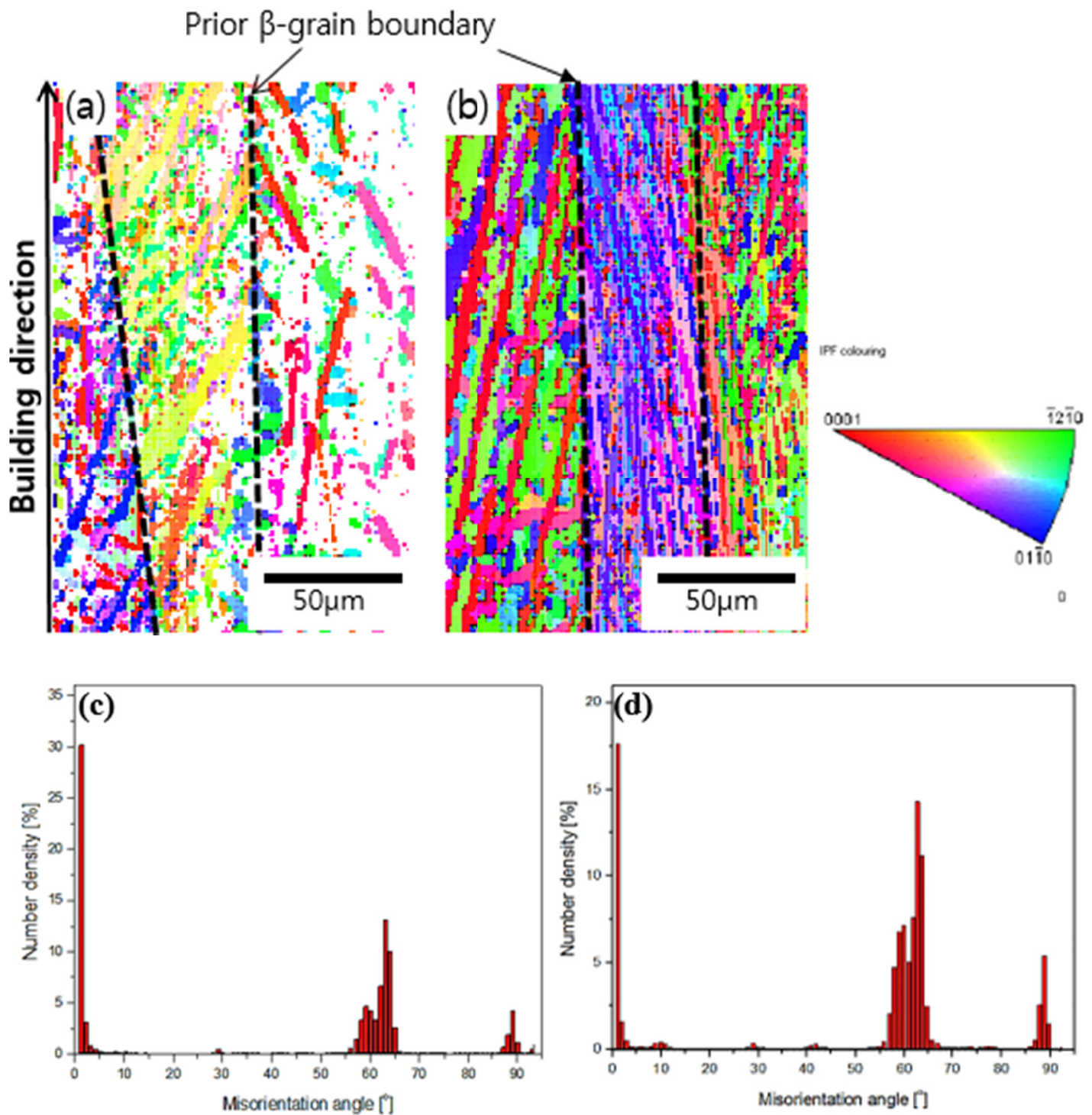

Fig. 4. EBSD grain orientation maps and misorientation angle distributions of SLMed Ti-6Al-4V alloy; (a,c) as-fabricated specimen and (b,d) heat-treated specimen
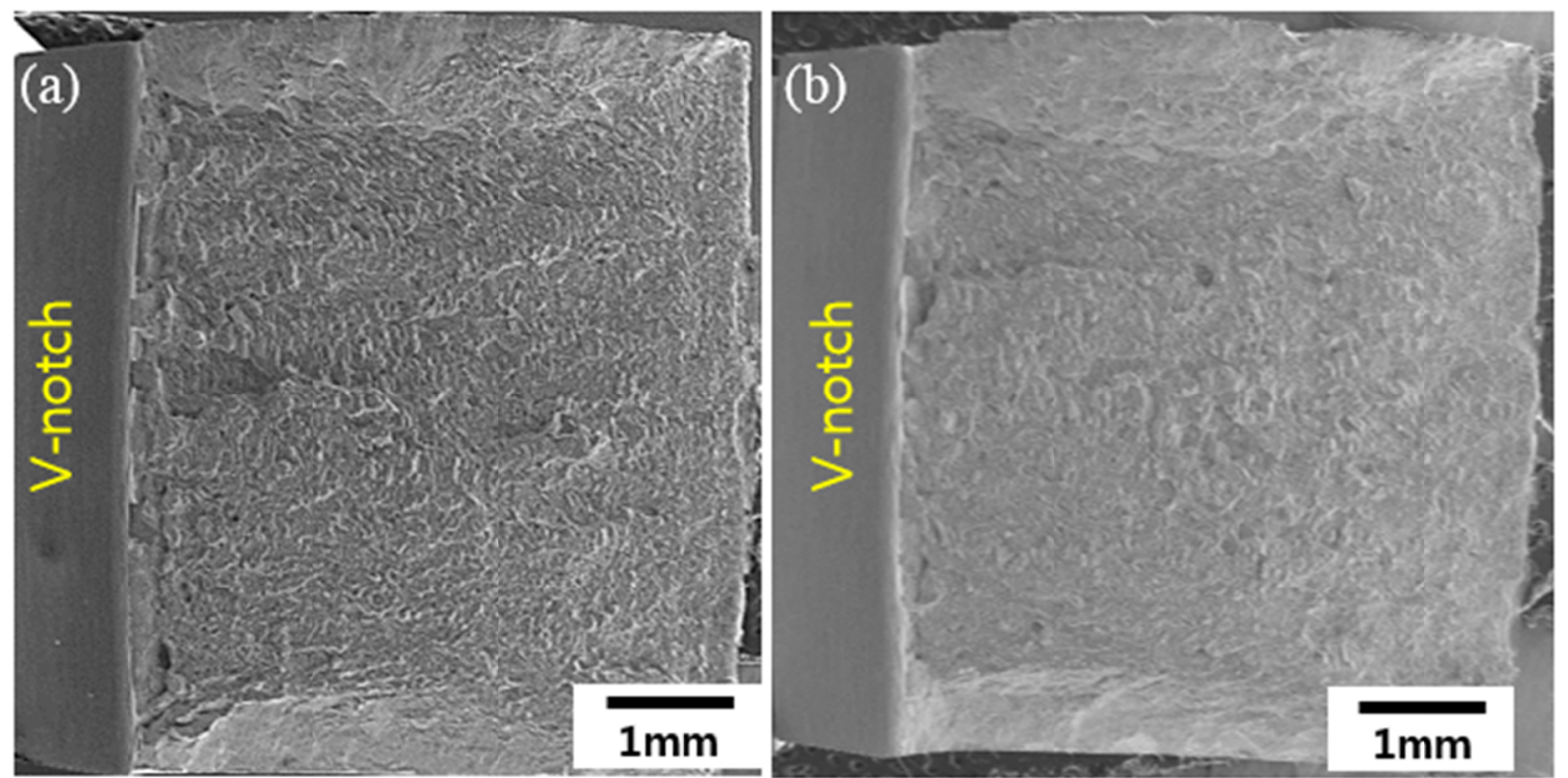

Fig. 5. Fracture surfaces of SLMed Ti64 alloy at low magnification; (a) as-fabricated specimen and (b) heat-treated specimen 
energy. However, as mentioned above, despite the macroscopically similar fracture surface, an approximately $20 \%$ increase in impact energy indicates that there are microscopic differences.

Fig. 6 shows the crack initiation area and crack propagation area observed to identify the difference in impact energy between the two specimens. In Fig. 6(a), the crack initiation areas of the two specimens show clear differences. Continuous stair-shaped cracks were formed in the opposite direction of the initial impact in the as-fabricated specimen, and relatively more curved cracks were formed in the heat-treated specimen. Impact energy can be differentiated by crack initiation and crack propagation, and the curved cracks found in the specimen are considered to undertake the role of increasing impact energy at crack initiation. In the crack propagation area (b), disk-type defects were observed, and they were very similar in size and shape to the defects found in OM observation (Fig. 1). Also, as more disk-type defects were observed on the fracture surface of the as-fabricated specimen, it is understood that such defects were caused by the initial microstructure. In other words, the disk-type defects accelerated crack propagation, which resulted in lower impact energy in the as-fabricated specimen. The measurement of maximum/minimum height through XRD computed tomography measured $3.75 \mathrm{~mm}$ for the as-fabricated specimen and $4.5 \mathrm{~mm}$ for the heat-treated specimen. This is due to the relatively curved shape fracture surface of the heat-treated surface, which results in relatively ductile material properties. Meanwhile, the residual raw particles observed in many other SLMed Ti64 alloys were not found in this study. It is considered that the complex interaction of microstructural change and defect reduction due to heat treatment caused the impact energy difference between the two specimens.

\section{Conclusions}

Microstructural observation of Ti64 alloy manufactured using the selective laser melting process confirmed that prior $\beta$ grain elongation along the heat release direction, and main acicular-type $\alpha^{\prime}$ martensite were formed inside the grain. X-ray diffraction pattern analysis and misorientation angle analysis identified that some $\alpha^{\prime}$ phases decomposed due to heat treatment, and dislocation density also decreased in the heat treatment process. The impact test measured average impact energies of $6.0 \mathrm{~J}$ and $7.3 \mathrm{~J}$ for the as-fabricated and heat-treated specimens,
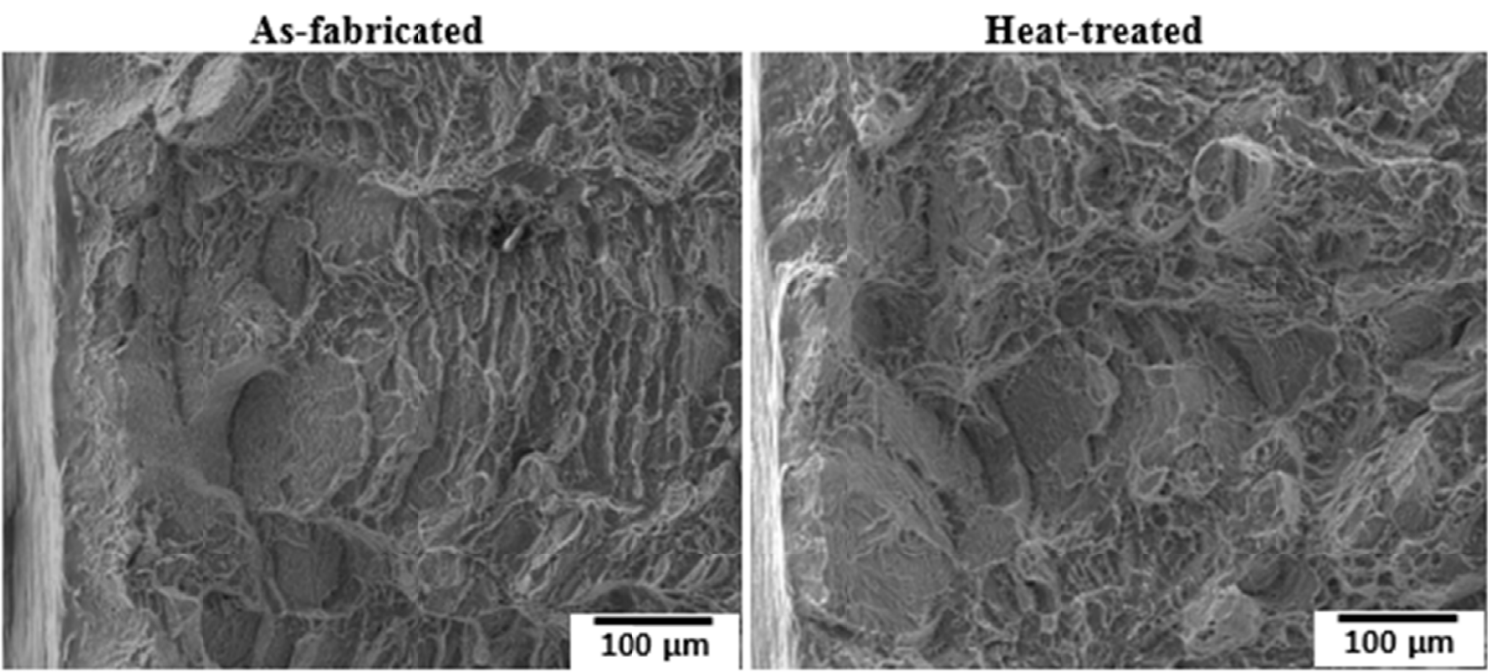

(a)
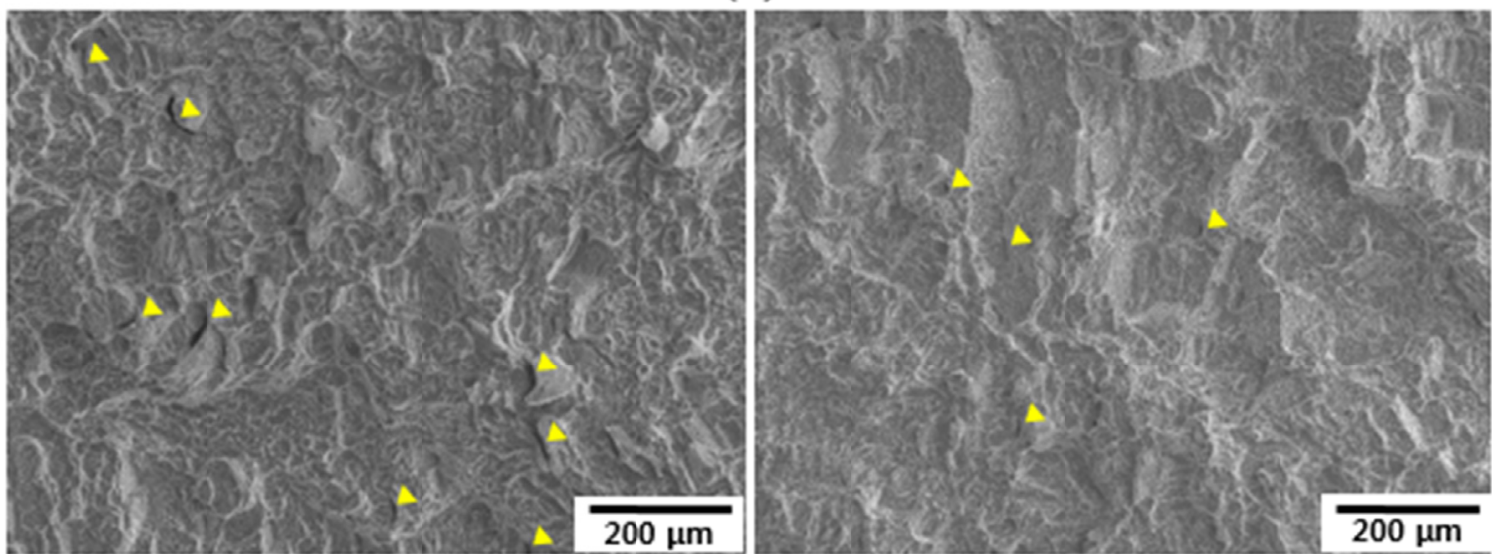

(b)

Fig. 6. Fracture surfaces showing (a) the crack initiation area and (b) crack propagation area 
1346

respectively, which indicated an approximate $20 \%$ increase after heat treatment. Such is caused by microstructural change according to heat treatment, and it was confirmed to be a difference caused by the decomposition of $\alpha^{\prime}$ phase, which has high brittleness. Macroscopic fracture surface observation after the impact test identified fracture surface characteristics similar to those of common brittle materials regardless of heat treatment. The heat-treated specimen featured a relatively more curved fracture surface in the crack initiation area and disk-type defects decreased in the crack propagation area.

\section{Acknowledgements}

This research was supported by Korea Institute of Materials Science.

\section{REFERENCES}

[1] H. Choi, J.M. Byun, W. Lee, S.R. Bang, Y.D. Kim, J. Korean Powder Metall. Inst. 23, 149 (2016).

[2] C. Qiu, N.J.E. Adkins, M.M. Attallah, Mater. Sci. Eng. A 578, 230 (2013).

[3] I. Gurrappa, Mater. Charact. 51, 131 (2003).

[4] F.H. Froes, H. Friedrich, J. Kiese, D. Bergoint, JOM 56, 40 (2004).

[5] L. Thijs, F. Verhaeghe, T. Craeghs, J.V. Humbeeck, J.P. Kruth, Acta Mater. 58, 3303 (2010).

[6] H.K. Rafi, T.L. Starr, B.E. Stucker, Int. J. Adv. Manuf. Technol. 69, 1299 (2013).

[7] B. Baufeld, O.V.D. Biest, R. Gault, Mater. Design 31, S106 (2010).

[8] M. Simonelli, Y.Y. Tse, C. Tuck, Metall. Mater. Trans. A 45A, 2863 (2014).

[9] C. Buirette, J. Huez, N. Gey, A. Vassel, E. Andrieu, Mater. Sci. Eng. A 618, 546 (2014).

[10] D.G. Hernandez, MS Thesis, TECNICO LISBOA 2014. 